\title{
Recombinant human bone morphogenetic protein -2 in combination with $\beta$-Tricalcium Phosphate and Platelet Rich Fibrin for Socket Preservation before Implant Placement
}

Khushboo Jeevan Durge ( $\nabla$ khushboodurge5@gmail.com )

Dr. Khushboo Jeevan Durge Senior Lecturer, Department of Periodontics Sharad Pawar Dental College, Datta Meghe Institute of Medical Sciences - Wardha Campus(Deemed to be University)

Vidya Sudhindra Baliga

Datta Meghe Institute of Medical Sciences - Wardha Campus

Shilpa Banglore Sridhar

Datta Meghe Institute of Medical Sciences - Wardha Campus

Prasad Vijayrao Dhadse

Datta Meghe Institute of Medical Sciences - Wardha Campus

Gayatri Chandrakant Ragit

Datta Meghe Institute of Medical Sciences - Wardha Campus

\section{Research note}

Keywords: Dental implant, socket preservation, rhBMP-2, PRF and $\beta$-TCP

Posted Date: August 28th, 2020

DOI: https://doi.org/10.21203/rs.3.rs-42632/v1

License: (c) (1) This work is licensed under a Creative Commons Attribution 4.0 International License. Read Full License

Version of Record: A version of this preprint was published at BMC Research Notes on February 15th, 2021. See the published version at https://doi.org/10.1186/s13104-021-05476-0. 


\section{Abstract}

Objectives - Periosteum is a rich source of osteoprogenitor cells, and flapless extraction technique allows for preservation of periosteum. Recombinant Bone Morphogenetic Protein-2 has osteoinductive capacity and has been exploited for bone augmentation. The aim of this study is to determine the effectiveness of rhBMP-2 for socket preservation along with $\beta$-TCP and PRF to enhance bone quality, clinically and radiographically.

Results- Minimal crestal bone changes were seen at 3 months compared to baseline values; bone loss of $0.6 \pm$ $0.13 \mathrm{~mm}$ at mesio-distal aspect, $0.5 \pm 0.13 \mathrm{~mm}$ at bucco-lingual aspect. At 3 months reentry, no residual bone particulate graft were seen in any of site. Clinical hardness of bone evaluated through tactile perception while drilling, prior to implant placement, was analogous to drilling into spruce or white pine wood. Histologic analysis confirmed the absence of residual bone graft indicating new bone formation.Complete radiographic fill was seen at 3 months. The patients in current study showed adequate bone formation in grafted sockets and required no additional augmentation during implant placement. Therefore, based on the results and within the limitations of study it can be suggested that, rhBMP-2 with PRF and $\beta$-TCP can be recommended for socket preservation prior to implant placement

\section{Introduction}

Currently endosseous implants have become the choice of therapy for the management of edentulous site .(1) (2) (3).Following extraction, however the alveolar process undergoes resorption as a result of osteoclastic activity leading to diminished alveolar ridge dimensions in both the vertical and horizontal planes.(4) Alveolar ridge alterations ranging from $40-60 \%$ have been reported to occur as early as three months after extraction. (5) This altered height and width present functional as well as aesthetic problems resulting in compromised rehabilitation. Non-grafted extraction sites may lose up to fifty percent of ridge width in first 12 months following removal of tooth. (6) An average reduction reported in width and height of the grafted extraction sites is minimal in contrast to non-grafted extraction sites, with the majority cases requiring no additional augmentation to have the implants placed.(7) Therefore, surgical approaches aiming at maintaining ridge volume by ridge preservation before implant placement have been proposed to be effective.

Platelet -rich fibrin (PRF) comprises of fibrin matrix enriched with platelets and growth factors. Hence is a powerful bioscaffold for tissue regeneration. (8)Alloplastic materials like tri-calcium phosphate (TCP) is regarded as a viable substitute to the autogenous bone or other bone substitutes.(9) An ability of PRF for regeneration can be intensified in a blend with bone substitutes. The Recombinant human bone morphogenetic protein-2 (rhBMP-2) reported to be promising in various bone augmentation procedures. (10) An animal study has reported noteworthy bone formation escorted with rhBMP-2 impregnated $\beta$-TCP scaffold in cranial bone defect model. (11) The utility of rhBMP-2 and Acellular Collagen Sponge (ACS) in extraction defects reported to be beneficial in reconstruction of buccal plate. It aid to maintain ridge configurations favoring implant placement 5 months later. (12)

The alveolar ridge dimensions are crucial for implant placement. Similarly, the inherent amount of vital bone formation in healing socket is also important. Therefore, the study was undertaken to evaluate clinically, radiographically, and histologically the effectiveness with ridge preservation performed using rh-BMP-2 in combination with $\beta$-TCP and PRF.

\section{Materials And Method}

Following informed consent, two patients who required extraction of teeth for reasons other than periodontitis were recruited. After proper examination and diagnosis, initial therapy consisting of oral hygiene instructions, supragingival 
and subgingival scaling were performed. (Table 1) Four sites were treated in two patients. The selected sites were examined, both clinically and radiographically (Table 2 ).

Table no 1 Full Mouth Papillary Bleeding Index (FMPBI) and Full Mouth Plaque Index (FMPI)

\begin{tabular}{|c|c|c|c|c|c|}
\hline \multicolumn{2}{|l|}{} & \multicolumn{2}{|c|}{ At Baseline } & \multicolumn{2}{c|}{ At 3 months } \\
\hline \multicolumn{2}{|l|}{} & FMPBI & FMPI & FMPBI & FMPI \\
\hline \multicolumn{2}{|c|}{ Case 1 } & \multicolumn{5}{l}{} \\
\hline Site & 11 & 0.5 & 0.4 & 0.4 & 0.4 \\
\hline Site & 12 & 0.5 & 0.4 & 0.3 & 0.3 \\
\hline Case 2 & & & & 0.5 \\
\hline Site & 46 & 0.5 & 0.5 & 0.5 & 0.5 \\
\hline Site & 47 & 0.5 & 0.5 & 0.5 & 0.5 \\
\hline Mean/SD & & $0.5 \pm 0$ & $0.45 \pm 0.05$ & $0.425 \pm 0.08$ & $0.425 \pm 0.08$ \\
\hline
\end{tabular}

Table no 2-Measurements at ridge prior tooth/root piece extraction (at baseline) and at 3 months (Post-operative) 


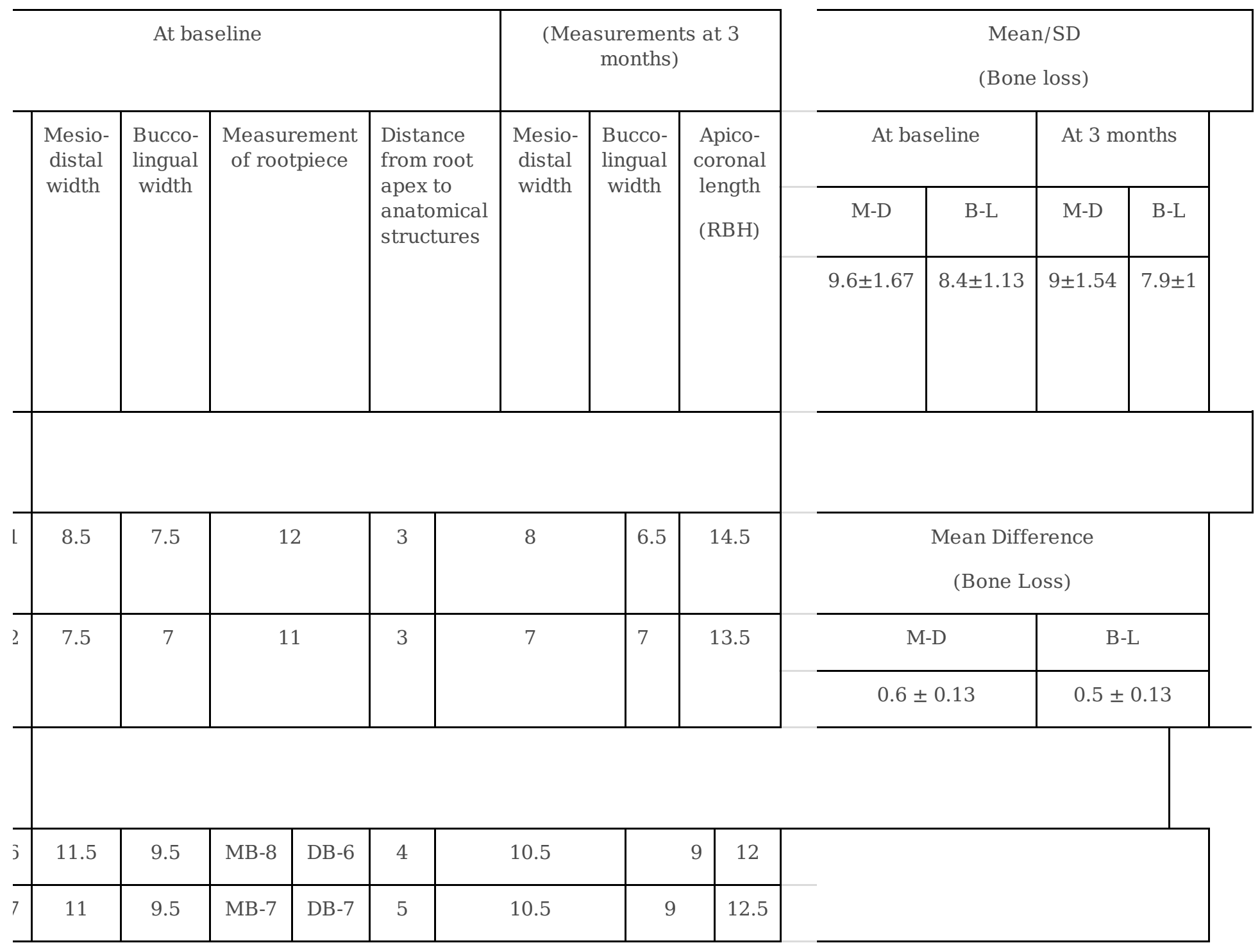

\section{Surgical procedure}

A pre-surgical rinse with chlorhexidine gluconate $0.12 \%$ mouthwash (Rexidine®, Indoco Remedies Ltd) for 2 minutes was advocated. After administration of local anaesthesia (Xicaine®, ICPA Health Products Limited) a minimal flap reflection was done. The flap reflection was not extended beyond $2 \mathrm{~mm}$ of alveolar crest. Minimally invasive periotomy was carried out with a Bard Parker Surgical blade number \#15 (Glassvan®, Niraj Industries Pvt Ltd) to facilitate atraumatic extraction without causing damage to the buccal plate. Consecutively, walls of the socket were verified for integrity. Twenty millilitres of venous blood was withdrawn in two test tubes from the antecubital vein. The blood was centrifuged (3000 rpm for 12 minutes) to obtain PRF. One part of PRF was mixed with $\beta$-TCP (OSTEON TM II Genoss Co.,Ltd, Korea) and rh-BMP2 (GibcoR, Recombinant Human Bone Morphogenetic protein-2, Life Technologies, Van Allen Way, Carlsbad, California) to enhance wound healing by filling the socket up to the level of the alveolar crest. The remaining clot was compressed to a membrane of high tensile strength. The membrane was then carefully placed covering the graft material. Approximation of the surgical site was done using a 3-0 silk suture. (Centisilk NonAsorbable Surgical Suture U.S.P). 
The patients were recalled after 3 months for implant placement. Following administration of local anaesthesia (Xicaine ${ }^{\circledR}$, ICPA Health Products Limited), an incision was given from line angle of adjacent teeth to elevate mucoperiosteal flap and expose the underlying bone. Alveolar ridge measurements were taken intrasurgically, and were compared with the preoperative alveolar dimensions (Table 2). A $2 \mathrm{~mm}$ trephine drill was initially used to harvest bone core for histologic examination. The bone tissue was moved to a fixture containing $10 \%$ neutral buffered formalin. Further it was sent to the laboratory for histologic evaluation. Osteotomy preparation was completed using sequential drills based on the size of the implant selected. An implant (Equinox, Myriad Plus TM implant system) of the largest possible dimension was placed according to manufacturer's recommendations and further follow-up was carried out .Four implants were placed in two patients. The biopsied tissue from the four sites, obtained prior to implant placement were evaluated, histologically (Fig.1)

\section{Discussion}

Healthy osseous contour provides a skeleton for peri-implant soft tissues. The purpose of atraumatic extraction is to minimize bone resorption and to maintain alveolar ridge dimensions during healing. In present study, socket preservation was done by using a combination of PRF, $\beta$-TCP and rh-BMP-2.After 3 months of ridge preservation clinical examination of the ridge revealed minimal dimensional changes ( mesio-distal bone loss $0.6 \pm 0.13 \mathrm{~mm}$ and bucco-lingual bone loss $0.5 \pm 1.13 \mathrm{~mm}$ ). The clinical hardness of bone evaluated during drilling, prior to implant placement, provided a tactile sensation analogous to drilling into spruce or white pine wood at all the four sites.(13) Although the density of bone could not be evaluated using Hounsfield units, dense to thick porous cortical bone on the crest and coarse trabecular bone underneath was seen on radiographic examination, suggesting D2 bone quality(14). Histologically, presence of vital, mineralized osteoid trabeculae along with soft tissue containing spindle nuclear cells indicating new bone formation was noted. All four implants achieved good primary stability.

As soft tissue grows six times faster than the bone tissue (15), in the present study the sockets were covered with a saddle of PRF membrane which prevented the gingival connective tissue down-growth. It prevented epithelial migration into the defect. It also held osseous graft in place. (16) Additionally, the membrane also aided in clot stabilization. PRF principally contain fibrin matrix rich in platelets, leukocytes. Cytokines such as IL-1 $\beta,-4$, and -6 , and growth factors such as PDGF, TGF-beta, IGF, EGF and VEGF are other important components. These are the key elements in bone regeneration. (17) Fibrin gels in coagulation cascade aids in fibrinogen molecules collaboration. This leads to a highly biocompatible three-dimensional fiber network. (18)Therefore, PRF resulted in improved wound healing and enhanced bone graft density and maturation. (19)

$\beta$-TCP is (purified, microcrystalline porous) form of calcium phosphate. A remarkable resorption of $\beta$-TCP particulate is estimated around 3 to 6 months after placement. Besides, particles become well-incorporated into new bone formation. This creates a dense cancellous matrix. Biodegradation of graft takes place by osteoclastic activity as well as chemical dissolution by tissue fluids. During implant placement, a solid new bone formation was evident which favored the placement of an ideal implant size.

The use of rhBMP-2 necessitates the use of a carrier for its oseoinductivity (20) Misch emphasized advantages of rhBMP-2 in new bone growth in patients requiring extraction. In present case series rhBMP-2 was used as an agent to promote socket repair as well to aid in ridge augmentation when combined with a part of $\beta$-TCP. Fiorellini et al (21) determined the efficacy of varying concentrations of rhBMP-2 in socket defects. The results showed profound bone growth when rhBMP-2 concentration was increased. Author also stated an ideal concentration for rhBMP-2 in grafting could be $1.5 \mathrm{mg} / \mathrm{mL}$. Therefore, in the present study $1.5 \mathrm{mg} / \mathrm{mL}$ concentration of rhBMP-2 was used. 
Various studies (22) (23)have supported the use of a mixture of $\beta$-TCP and rh-BMP- 2 to facilitate increased bone formation in the defects. Therefore, in this study rhBMP-2 was used in combination with $\beta$-TCP to promote bone growth.

\section{Limitations}

The present study describes results obtained in a small sample. Although there is evidence of good quality bone formation in a short time period following the use of a combination of rhBMP-2, $\beta$-TCP and PRF, larger population studies may further improve the significance of the results obtained. PRF was used to cover and hold the graft in place. The increase in keratinized tissue thickness following the PRF membrane placement was not evaluated. Additionally, only six months follow-up results have been reported, further long term evaluation of the patients would be beneficial. Even though pre-operative $\mathrm{CBCT}$ was taken but due to cost concerns and unwillingness of the patient the post-operative CBCT could not be taken.

\section{Abbreviations}

-rhBMP-2-recombinant bone morphogenetic protein, $\beta$-TCP- beta-tricalcium phosphate, PRF-platelet rich fibrin, PDGFplatelet-derived growth factor, TGF-beta transforming growth factors, IGF-the insulin-like growth factor, EGF - epithelial growth factor, VEGF-vascular endothelial growth factor. Full Mouth Papillary Bleeding Index (FMPBI), Full Mouth Plaque Index (FMPI), MB-Mesio-buccal root, DB-Disto-buccal root, RBH-Residual bone height- measured from alveolar crest to anatomical structure, M-D Mesiodistal width, B-L Buccolingual width

\section{Declarations}

\section{Acknowledgements-None}

\section{Authors' contributions}

Primary author KJD performed the surgical procedures and drafted the manuscript. Second author VSB conducted the examinations, and reviewed the manuscript. Third author SBS reviewed \&revised the manuscript. Fourth author PVD revised the final writing of the manuscript .Fifth author GCR assisted in all surgical procedures and helped in drafting the manuscript through literature search. All authors have read and approved the manuscript.

Funding -None

Availability of data and materials-The data sets used and/or analyzed during the current study are available from the corresponding author or reasonable request.

Ethics approval and consent to participate -The study protocol No- DMIMS(DU)/IEC/2016-17-5080 was first approved by the Ethical Committee of Datta Meghe Institute of Medical Sciences, Sawangi (Meghe), Wardha, Maharashtra (India), and a written informed consent was obtained from all the patients.

\section{Consent for Publication-Not applicable}

Competing interests-The authors declare that they have no competing interests.

\section{Author details-}


1. Assistant Professor, Department of Periodontics, 2. Professor, Department of Periodontics, 3. Assistant Professor , Department of Periodontics 4. Professor and Head, Department of Periodontics 5. Postgraduate Student, Department of Periodontics, Sharad Pawar Dental College Sawangi (Meghe),Datta Meghe Institute of Medical Sciences (Deemed to be University) Wardha, Maharashtra State, India .

\section{References}

1. Berglundh T, Persson L, Klinge B. A systematic review of the incidence of biological and technical complications in implant dentistry reported in prospective longitudinal studies of at least 5 years. Journal of clinical periodontology. 2002 Dec;29:197-212.

2. Buser D, Dula K. Localized ridge augmentation using guided bone regeneration. I. Surgical procedure in the maxilla. Int J Periodontics Restorative Dent 1993; 13:29-45.

3. Adell R, Lekholm U, Brånemark PI, Lindhe J, Rockler B, Eriksson B, Lindvall AM, Yoneyama T, Sbordone L. Marginal tissue reactions at osseointegrated titanium fixtures. Swedish dental journal. Supplement. 1985;28:175-81.

4. Pietrokovski J, Massler M. Alveolar ridge resorption following tooth extraction. Journal of Prosthetic Dentistry. 1967 Jan 1;17(1):21-27.

5. Schropp L, Wenzel A, Kostopoulos L, Karring T. Bone healing and soft tissue contour changes following singletooth extraction: a clinical and radiographic 12-month prospective study. International Journal of Periodontics \& Restorative Dentistry. 2003 Aug 1;23(4).

6. Araújo M, Linder E, Wennström J, Lindhe J. The influence of Bio-Oss Collagen on healing of an extraction socket: an experimental study in the dog. International Journal of Periodontics \& Restorative Dentistry. 2008 Apr 1;28(2).

7. Barone A, Ricci M, Tonelli P, Santini S, Covani U. Tissue changes of extraction sockets in humans: a comparison of spontaneous healing vs. ridge preservation with secondary soft tissue healing. Clinical oral implants research. 2013 Nov;24(11):1231-1237.

8. Kang Y H, Jeon S H, Park J Y, Chung JH, Choung Y H, Choung HW, Kim E S, Choung P H. Platelet-rich fibrin is a Bio scaffold and reservoir of growth factors for tissue regeneration. Tissue Engineering Part A. 2010 Dec 21;17(34):349-359.

9. Bhatt, A.K., Pant, V.A., Pandey, M. 2015. Alveolar Ridge Preservation with BetaTricalcium Phosphate Bone Graft and Implant Placement: A Case Report. IJSS Case Reports \&Reviews, 1:11:24-32.

10. Ramly EP, Alfonso AR, Kantar RS, Wang MM, Siso JR, Ibrahim A, Coelho PG, Flores RL. Safety and efficacy of recombinant human bone morphogenetic protein-2 (rhBMP-2) in craniofacial surgery. Plastic and Reconstructive Surgery Global Open. 2019 Aug;7(8).

11. Lim HP, Mercado-Pagan AE, Yun KD, Kang SS, Choi TH, Bishop J, Koh JT, Maloney W, Lee KM, Yang YP, Park SW. The effect of rhBMP-2 and PRP delivery by biodegradable $\beta$-tricalcium phosphate scaffolds on new bone formation in a non-through rabbit cranial defect model. Journal of Materials Science: Materials in Medicine. 2013 Aug 1;24(8):1895-1903.

12. Coomes AM, Mealey BL, Huynh-Ba G, Barboza-Arguello C, Moore WS, Cochran DL. Buccal bone formation after flapless extraction: a randomized, controlled clinical trial comparing recombinant human bone morphogenetic protein 2/absorbable collagen carrier and collagen sponge alone. Journal of periodontology. 2014 Apr;85(4):52535.

13. Misch CE. The implant quality scale: a clinical assessment of the health-disease continuum. Oral Health. 1998 Jul 1;88(7):15-20.

14. Misch CE. Bone character: second vital implant criterion. Dent today. 1988 Jun;7(5):39-40. 
15. Wikesjö UM, Selvig KA, Zimmerman G, Nilvéus R. Periodontal repair in dogs: healing in experimentally created chronic periodontal defects. Journal of periodontology. 1991 Apr;62(4):258-263.

16. Dahlin C, Linde A, Gottlow J, Nyman S. Healing of bone defects by guided tissue regeneration. Plastic and reconstructive surgery. 1988 May 1;81(5):672-6.

17. Dohan D M, Choukroun J, Diss A, Dohan SL, Dohan AJ, Mouhyi J, Gogly B. Plateletrich fibrin (PRF): a secondgeneration platelet concentrate. Part II: platelet-related biologic features. Oral Surgery, Oral Medicine, Oral Pathology, Oral Radiology, and Endodontology. 2006 Mar 1;101(3):e45-50.

18. Bensaıd W, Triffitt JT, Blanchat C, Oudina K, Sedel L, Petite H. A biodegradable fibrin scaffold for mesenchymal stem cell transplantation. Biomaterials. 2003 Jun 1;24(14):2497-2502.

19. Marx RE, Carlson ER, Eichstaedt RM, Schimmele SR, Strauss JE, Georgeff KR. Platelet-rich plasma: growth factor enhancement for bone grafts. Oral Surgery, Oral Medicine, Oral Pathology, Oral Radiology, and Endodontology. 1998 Jun 1;85(6):638-46.

20. Maus U, Andereya S, Gravius S, Ohnsorge JA, Niedhart C, Siebert CH. BMP-2 incorporated in a tricalcium phosphate bone substitute enhances bone remodeling in sheep. Journal of biomaterials applications. 2008 May;22(6):559-576.

21. Fiorellini JP, Howell TH, Cochran D, Malmquist J, Lilly LC, Spagnoli D, Toljanic J, Jones A, Nevins M. Randomized study evaluating recombinant human bone morphogenetic protein-2 for extraction socket augmentation. Journal of periodontology. $2005 \mathrm{Apr} ; 76(4): 605-13$.

22. Ohyama, T., Kubo, Y., Iwata, H. and Taki, W.Beta-tricalcium Phosphate Combined with Recombinant Human Bone Morphogenetic Protein-2: A Substitute for Autograft, used for Packing Interbody Fusion Cages in the Canine Lumbar Spine, Neurologiamedica-chirurgica (Tokyo), 2004, 44(5): 234-240.

23. Hoshino M, Egi T, Terai H, Namikawa T, Takaoka K. Repair of long intercalated rib defects using porous betatricalcium phosphate cylinders containing recombinant human bone morphogenetic protein-2 in dogs.

Biomaterials. 2006 Oct 1;27(28):4934-4940.

\section{Figures}




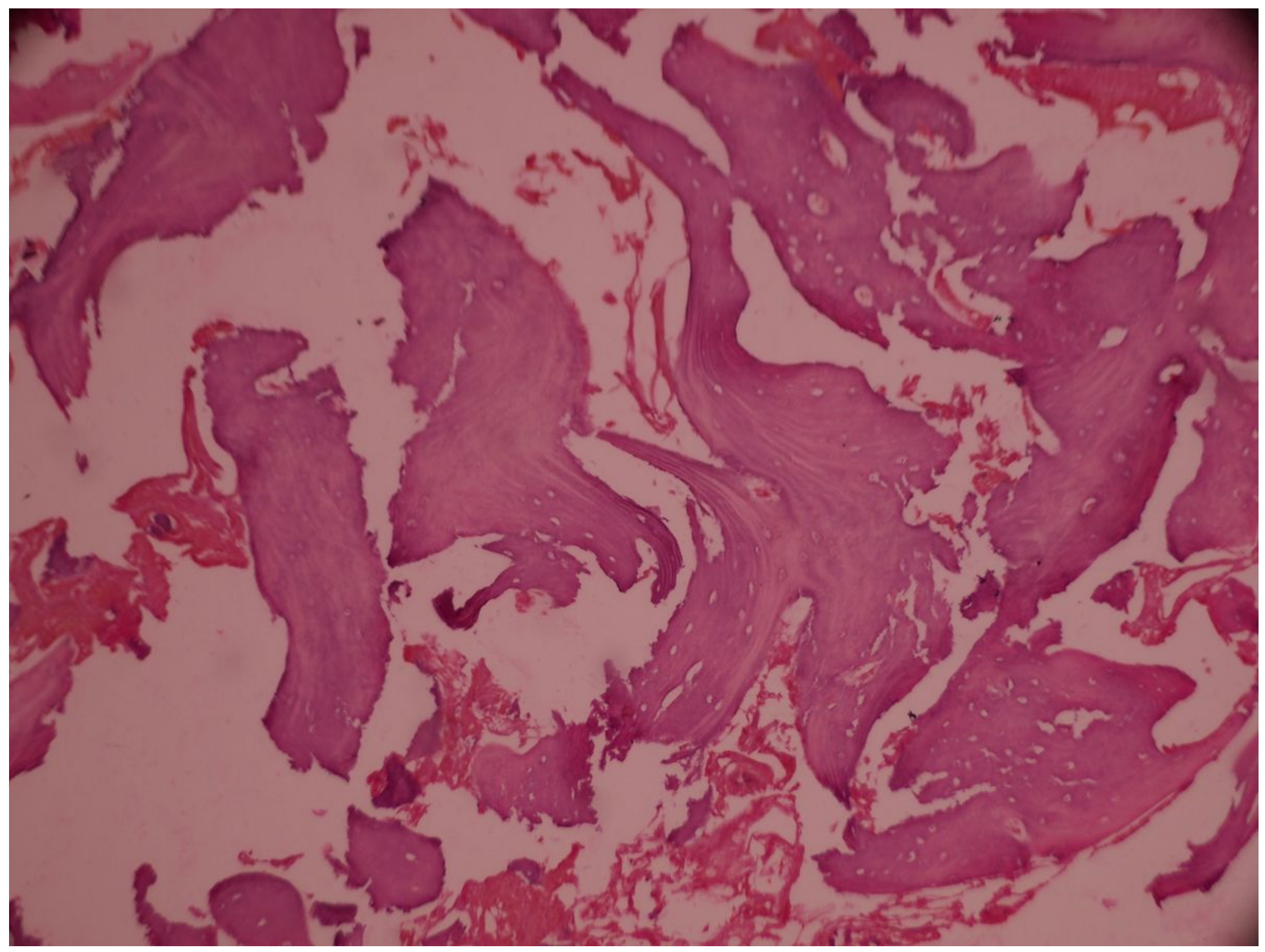

Figure 1

Implant placement

\section{Supplementary Files}

This is a list of supplementary files associated with this preprint. Click to download.

- FigS1.jpg

- FigS2.jpg

- FigS3.jpg

- FigS4.jpg

- FigS5.jpg

- FigS6.jpg

- FigS7.jpg

- FigS8.jpg

- FigS9.jpg 